\title{
Short communication: Influence of an aqueous myrrh suspension on yogurt culture bacteria over yogurt shelf life
}

\author{
M. Alhejaili, D. W. Olson, C. Velásquez, M. Janes, C. Boeneke, and K. J. Aryana* \\ School of Nutrition and Food Sciences, Louisiana State University Agricultural Center, Baton Rouge 70803
}

\section{ABSTRACT}

Myrrh is an essential oil and natural flavoring approved by the US Food and Drug Administration, and it has antibacterial and antifungal activity against pathogens. Our objective was to determine the effect of an aqueous myrrh suspension on Streptococcus thermophilus and Lactobacillus delbrueckii ssp. bulgaricus counts in peptone solution and yogurt, as well as $\mathrm{pH}$ and titratable acidity of yogurt during $5 \mathrm{wk}$ of storage at 1 to $4^{\circ} \mathrm{C}$. The myrrh suspension $(10 \% \mathrm{wt} / \mathrm{vol})$ was prepared and incorporated into a pure culture dilution in peptone and into yogurt mix at a $1 \%$ (vol/vol) level. A control with no myrrh was also prepared, and 3 replications were conducted. Streptococcus thermophilus were enumerated using Streptococcus thermophilus agar with aerobic incubation at $37^{\circ} \mathrm{C}$ for $24 \mathrm{~h}$, and Lactobacillus delbrueckii ssp. bulgaricus were enumerated using de Man, Rogosa, and Sharpe agar adjusted to $\mathrm{pH}$ 5.2, with anaerobic incubation at $43^{\circ} \mathrm{C}$ for $72 \mathrm{~h}$. During the 8-h period after inoculation, $S$. thermophilus and $L$. delbrueckii ssp. bulgaricus counts in peptone solution at $37^{\circ} \mathrm{C}$ and $43^{\circ} \mathrm{C}$, respectively, were not significantly different in the presence or absence of the aqueous myrrh suspension. Counts of $S$. thermophilus in yogurt containing myrrh (mean $\pm \mathrm{SD} ; 4.96 \pm 0.58 \log \mathrm{cfu} / \mathrm{mL}$ ) were not significantly different from those in the control yogurt $(4.87 \pm 0.39 \log \mathrm{cfu} / \mathrm{mL})$. The $\log$ counts for $L$. delbrueckii ssp. bulgaricus in yogurt containing myrrh $(5.04 \pm 1.44 \log \mathrm{cfu} / \mathrm{mL})$ and those of the control (5.52 $\pm 1.81 \log \mathrm{cfu} / \mathrm{mL}$ ) did not differ, and the counts remained within $1 \log$ of each other throughout 5 wk of storage. The $\mathrm{pH}$ of the yogurts containing the aqueous myrrh suspension was not significantly different from that of the control yogurts, and their $\mathrm{pH}$ values were within $0.1 \mathrm{pH}$ unit of each other in any given week. Titratable acidity values remained steady around 1.1 to $1.2 \%$ lactic acid for both yogurt types throughout the

Received March 26, 2018.

Accepted October 16, 2018.

*Corresponding author: karyana@agcenter.lsu.edu storage period, with no significant differences between them. Yogurt culture bacteria can survive in the presence of a myrrh suspension in yogurt with no significant change in $\mathrm{pH}$ or titratable acidity. Therefore, it may be beneficial to add an aqueous myrrh suspension to yogurt.

Key words: myrrh, antimicrobial, yogurt culture

\section{Short Communication}

Myrrh is extracted from Commiphora trees of the Burseraceae family. Species in the Commiphora genus are small trees or shrubs with short, thorny branches and number more than 200 (Hanuš et al., 2005); Commiphora myrrha is a variable species found in parts of Saudi Arabia and northeast Africa as far south as northeast Kenya. Myrrh, a brown powder, contains gum, resin, volatile oil, and other compounds (Mohamed et al., 2016).

Myrrh is a safe, natural flavoring substance approved by the US Food and Drug Administration (FDA, 2018; 21CFR172.510) and functions as a preservative. Extracts of many types of plants have been used as flavoring and seasoning agents in foods and beverages and as folk medicines and food preservatives since ancient times. Myrrh adds characteristic flavor and prolongs the shelf life of foods by its antioxidant, bacteriostatic, and bactericidal activities (Kim et al., 2011).

Myrrh has considerable antimicrobial activity and is used to cure a variety of diseases. It has antibacterial activity against standard pathogenic strains of Escherichia coli, Staphylococcus aureus, and Pseudomonas aeruginosa and antifungal activity against Candida albicans (Lotfy et al., 2006). Furthermore, it shows strong inhibitory activity against Salmonella enterica serovar Typhimirium, E. coli O157:H7, and Listeria monocytogenes on lettuce (Kim et al., 2011). Myrrh has antibacterial and antifungal properties because it contains sesquiterpenes (furanodiene-6-one and methoxyfuranoguaia-9-ene-8-one) and furanosesquiterpenoids [3-methoxy-4-furanogermacra-10(15)-dien6-one, 2-methoxy-4-furanogermacra-1(10)-en-6-one, furanogermacra-1(10)-4-dien-6-one, and curzerenone 
(6,7-dihydro-5-isopropenyl-3,6-dimethyl-6-vinyl benzofuran-4-one)] (Mohamed et al., 2016). Myrrh, along with honey and bee propolis, can help cure chronic nonhealing wounds such as diabetic foot disease (Lotfy et al., 2006). In the Middle Eastern region, the traditional way of taking myrrh as a medicine to treat a sore throat or a cold is by adding $1.67 \mathrm{~mL}$ of myrrh to $113 \mathrm{~g}$ of boiled water and consuming a teaspoon of $1 \%$ myrrh supernatant suspension daily (Fetrow and Avila, 2004). Boiling water enhances the medicinal (antimicrobial) efficacy of the myrrh supernatant compounds and does not inhibit the antimicrobial effect of the myrrh supernatant compounds (Fetrow and Avila, 2004).

Several studies have evaluated the health benefits provided by consumption of yogurt starter culture $(S$. thermophilus and L. delbrueckii ssp. bulgaricus) and the safety of yogurt consumption. Streptococcus thermophilus has many health benefits including reducing the occurrence of acute diarrhea and the level of nasal colonization of the pathogenic bacteria Streptococcus pneumoniae, Staphylococcus aureus, and $\beta$-hemolytic streptococci. Furthermore, S. thermophilus along with L. delbrueckii ssp. bulgaricus can reduce cholesterol assimilation (Sharma et al., 2014). The consumption of lactic acid bacteria (LAB) has several benefits, including enhancing the immune system; improving the intestinal tract by controlling irritable bowel syndrome, inflammatory bowel disease, and suppressing endogenous and exogenous pathogens; reducing symptoms of lactose intolerance; and reducing the risk of certain cancers (Parvez et al., 2006). Although yogurt consumption provides various health benefits and is almost always safe because of its low $\mathrm{pH}$ and inhibitory substances produced by added cultures, food poisoning outbreaks from E. coli O157:H7, Salmonella Typhimurium, staphylococci, and other pathogens in yogurt have been reported, as summarized by Aryana and Olson (2017). Myrrh can act as a pathogen inhibitor, flavoring agent, and a preservative. Pathogenic mutations that can survive low $\mathrm{pH}$ conditions are a possibility. Myrrh would add an additional barrier or hurdle for a potential pathogen, creating another layer of safety in this widely consumed product for gut health. Therefore, it would be beneficial to find ways to further decrease food safety risks by using myrrh.

The effect of various essential oils (EO) on the viability of LAB in dairy starter cultures and dairy products and on the viability of spoilage and pathogenic microorganisms has been studied. Marcial et al. (2016) reported that oregano EO did not affect LAB starter culture viability in cheese but protected it from growth of spoilage organisms. Likewise, Moro et al. (2015) reported that rosemary EO did not affect growth of
LAB in fortified cheese but inhibited Clostridium spp. However, Kostova et al. (2014) found that Lactobacillus species and $S$. thermophilus with Lactococcus lactis were inhibited by a $0.05 \%$ concentration of dill EO and killed by a $0.5 \%$ concentration. Çakmakçi et al. (2014) reported that black cumin EO decreased LAB counts in butter during storage. De Carvalho et al. (2015) recommended exercising caution when adding Thymus vulgaris $\mathrm{L}$. EO to cheese models because of the more severe inhibiting effects on cheese starter cultures than on pathogenic bacteria (Staphylococcus aureus and Listeria monocytogenes). Therefore, different EO at various concentrations have different effects on viability of LAB.

Because of the many potential beneficial effects provided by myrrh (flavor, preservative, and activity against pathogenic microorganisms), we hypothesized that an aqueous myrrh suspension could be incorporated into yogurt with potentially beneficial results if $S$. thermophilus and L. delbrueckii ssp. bulgaricus are not adversely affected by myrrh. To the best of our knowledge, whether myrrh has an antimicrobial effect on yogurt culture bacteria has not been reported in the literature. Therefore, the objective was to determine whether myrrh has antimicrobial effects on S. thermophilus and L. delbrueckii ssp. bulgaricus in pure form and in yogurt. We also investigated whether $\mathrm{pH}$ and titratable acidity in yogurt would be affected by the presence of myrrh.

Myrrh gum (Commiphora myrrha; country of origin: Eritrea; packed by Mond Trading Company, Toronto, ON, Canada) was dissolved in boiling distilled water to make a 10\% (wt/vol) suspension. The myrrh suspension was set for $1 \mathrm{~h}$ at room temperature for cooling. The suspension was centrifuged $\left(3,677 \times g, 5 \mathrm{~min}, 20^{\circ} \mathrm{C}\right.$; Accuspin 400 centrifuge, Fisher Scientific, Osterode, Germany), and only the supernatant was collected.

A $0.3-\mathrm{mL}$ aliquot of myrrh supernatant (10\% wt/ vol) was added to $3 \mathrm{~mL}$ of either freshly thawed pure cultures of $S$. thermophilus ST-M5 (approximately $1 \times$ $10^{11} \mathrm{cfu} / \mathrm{g} ;$ Chr. Hansen, Milwaukee, WI; Muramalla and Aryana, 2011) or L. delbrueckii ssp. bulgaricus LB-12 $\left(2.5 \times 10^{10} \mathrm{cfu} / \mathrm{g}\right.$ according to the certificate of analysis from Chr. Hansen) separately diluted with $26.7 \mathrm{~mL}$ of $0.1 \%$ sterilized peptone solution (Bacto Peptone, Difco/Becton, Dickinson and Co., Sparks, MD) to form a $1 \%$ myrrh supernatant suspension, with a total myrrh concentration of $0.1 \%$. The peptone solution was stored at $37^{\circ} \mathrm{C}$ for the $S$. thermophilus ST-M5 assay and at $43^{\circ} \mathrm{C}$ for the L. delbrueckii ssp. bulgaricus LB-12 assay. The inoculated myrrh supernatant was pour plated with M17 agar (Oxoid, Basingstoke, UK) containing $1 \%$ lactose (Oxoid) for S. thermophilus ST-M5 and 
with de Man, Rogosa and Sharpe (MRS) agar (Difco) for $L$. delbrueckii ssp. bulgaricus LB-12 in duplicate at $0,2,4,6$, and $8 \mathrm{~h}$ after inoculation. All M17-lactose plates were incubated aerobically at $37^{\circ} \mathrm{C}$ for $24 \mathrm{~h}$, and all MRS plates for $L$. delbrueckii ssp. bulgaricus were incubated anaerobically at $43^{\circ} \mathrm{C}$ for $72 \mathrm{~h}$. After incubation, a Quebec Darkfield Colony Counter (Leica Inc., Buffalo, NY) was used to enumerate the colonies.

Whole milk $(7.57 \mathrm{~L})$ in each of 2 pails was heated to $85^{\circ} \mathrm{C}$, held at that temperature for $30 \mathrm{~min}$, cooled to $40^{\circ} \mathrm{C}$, and then inoculated with $2 \mathrm{~mL}$ of freshly thawed pure cultures of $S$. thermophilus ST-M5 (Chr. Hansen) and L. delbrueckii ssp. bulgaricus LB-12 (Chr. Hansen). Myrrh supernatant $(75.7 \mathrm{~mL})$ was added to 1 of the 2 pails to form a $1 \%$ supernatant suspension, and the contents in the other pail served as a control. After mixing, yogurt mixes were poured into 355-mL Reynolds RDC212 Del-Pak Combo-Pak containers (Alcoa Inc., Pittsburgh, PA) and incubated at $40^{\circ} \mathrm{C}$ to $\mathrm{pH} 4.6$ before cooling to between 1 and $4^{\circ} \mathrm{C}$. Three replications were performed.

Yogurt was serially diluted with $0.1 \%$ (wt/vol) sterilized peptone solution. Each dilution was pour plated with Streptococcus thermophilus agar made in our laboratory (Dave and Shah, 1996) for enumerating $S$. thermophilus and MRS agar adjusted to pH 5.2 (Dave and Shah, 1996) for enumerating L. delbrueckii ssp. bulgaricus. Plating was conducted in duplicate at 0 , $1,2,3,4$, and 5 wk after yogurt manufacturing. All Streptococcus thermophilus agar plates were incubated aerobically at $37^{\circ} \mathrm{C}$ for $24 \mathrm{~h}$, and all MRS plates were incubated anaerobically at $43^{\circ} \mathrm{C}$ for $72 \mathrm{~h}$. A Quebec Darkfield Colony Counter (Leica Inc.) was used to assist in enumerating the colonies.

The $\mathrm{pH}$ of the yogurts was measured with an UltraBasic $\mathrm{pH} / \mathrm{mV}$ Meter (Denver Instrument Co., Arvada, $\mathrm{CO})$ at $5^{\circ} \mathrm{C}$ at $0,1,2,3,4$, and 5 wk of storage. The $\mathrm{pH}$ electrode was calibrated with $\mathrm{pH} 7.00$ and 4.00 buffer solutions (VWR International, West Chester, PA) before use. Titratable acidity was measured weekly for 5 wk by weighing $9 \mathrm{~g}$ of yogurt in a white evaporating dish, adding 3 drops of phenolphthalein indicator, and titrating with $0.1 \mathrm{~N} \mathrm{NaOH}$ to a faint pink color; titratable acidity was expressed as percent lactic acid (Wehr et al., 2004).

The log plate count, $\mathrm{pH}$, and titratable acidity data were analyzed as a randomized block design with repeated measures using PROC MIXED in SAS software (version 9.4; SAS Institute Inc., Cary, NC). Time was considered a random effect. Slopes of regression lines of $\log$ counts as a function of time represent the net growth or decline of the bacteria over time, and a comparison of the slopes of the regression lines between the myrrh-containing yogurt and the control would provide information about the effect of the presence of myrrh on the growth of these bacteria in yogurt. Significant differences in slopes of regression lines were tested using a random coefficient model by examining the significance of the myrrh (presence vs. absence) and time (hours after inoculation) interaction term in the ANOVA. PROC REG was also used to determine whether the regression lines were a good fit to the data points $\left(\mathrm{R}^{2}\right.$ values). Significance was set at $\alpha=0.05$.

We did not analyze the aqueous extracts of myrrh in this study. Although myrrh contains antimicrobial substances, the amount of active compounds present in the aqueous extract was not known and it is unclear whether sufficient quantity exists to exert an antimicrobial effect. Also, the effect of various extraction procedures and solvents on the amount of active compounds that enter the suspension is not known and could be the subject of a future study. Compounds within extracts of myrrh resin have been identified by GC-MS analysis, as reported by Hanuš et al. (2008) and Fraternale et al. (2011).

Log counts of $S$. thermophilus ST-M5 in peptone solution as influenced by myrrh at $0,2,4,6$, and $8 \mathrm{~h}$ are shown in Figure 1a. Counts in the presence and absence of myrrh remained steady around $9.9 \mathrm{log} \mathrm{cfu} /$ $\mathrm{mL}$, ranging from (mean $\pm \mathrm{SD}$ ) $9.80 \pm 0.03$ to 10.08 $\pm 0.05 \log \mathrm{cfu} / \mathrm{mL}$. We detected no significant differences in S. thermophilus log counts between the myrrh samples and controls or in the slopes of the regression lines for $S$. thermophilus log counts versus time for myrrh samples and control. The $1 \%$ myrrh supernatant was not strong enough to kill $S$. thermophilus ST-M5 bacteria suspended in a peptone solution.

Log counts of L. delbrueckii ssp. bulgaricus LB-12 in peptone solution as influenced by myrrh at $0,2,4$,

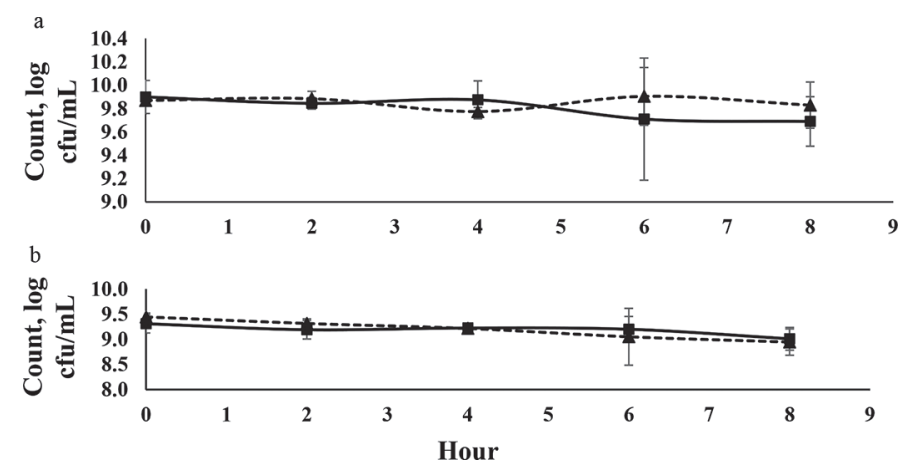

Figure 1. Log counts of (a) Streptococcus thermophilus ST-M5 and (b) Lactobacillus delbrueckii ssp. bulgaricus LB-12 counts in peptone water in the presence $(\boldsymbol{\Lambda})$ and absence (ם) of myrrh over the 8-h experiment. Error bars represent SD. 
6 , and $8 \mathrm{~h}$ are shown in Figure 1b. Counts decreased slightly from (mean $\pm \mathrm{SD}$ ) $9.39 \pm 0.09$ to $9.13 \pm 0.06$ $\log \mathrm{cfu} / \mathrm{mL}$ for the control yogurt and from $9.56 \pm 0.03$ to $9.17 \pm 0.02 \log \mathrm{cfu} / \mathrm{mL}$ for the myrrh-containing yogurt during the 8-h experiment. As observed for $S$. thermophilus, we detected no significant difference in $L$. delbrueckii ssp. bulgaricus log counts between the myrrh samples and controls or in the slopes of the regression lines for L. delbrueckii ssp. bulgaricus log counts versus time after inoculation of the myrrh-containing samples versus controls. Again, the 1\% myrrh supernatant concentration was not strong enough to kill the $L$. delbrueckii ssp. bulgaricus LB-12 bacteria.

For yogurt shelf-life study, S. thermophilus ST-M5 $\log$ counts as influenced by myrrh throughout $5 \mathrm{wk}$ of storage are shown in Figure 2a. Initial counts (mean \pm $\mathrm{SD})$ for $S$. thermophilus ST-M5 $(4.68 \pm 0.33 \mathrm{log} \mathrm{cfu} / \mathrm{g}$ for the control and $4.40 \pm 0.26 \mathrm{log} \mathrm{cfu} / \mathrm{g}$ for the myrrhcontaining yogurt) in the present study were lower than the approximately 8 to $9 \log \mathrm{cfu} / \mathrm{g}$ reported by Dave and Shah (1997) and Vinderola et al. (2000). Microbial counts for myrrh and control increased 1.01 and 0.63 $\log \mathrm{cfu} / \mathrm{g}$, respectively, over time from 0 to $5 \mathrm{wk}$. The intercept, slope of the regression line, $t$-value, $P$-value, and $\mathrm{R}^{2}$ value for $S$. thermophilus $\log$ counts as a function of storage time are shown in Table 1. We detected no significant difference in $S$. thermophilus log counts between the myrrh-containing yogurts (mean $\pm \mathrm{SD}$; $4.96 \pm 0.58 \log \mathrm{cfu} / \mathrm{mL})$ and the control $(4.87 \pm 0.39$ $\log \mathrm{cfu} / \mathrm{mL}$ ) or in the slopes of the regression lines for S. thermophilus log counts versus time during storage of the yogurts. The $1 \%$ myrrh supernatant was not strong enough to kill $S$. thermophilus ST-M5 bacteria in yogurt. The symbiotic relationship between $S$. thermophilus and L. delbrueckii ssp. bulgaricus in yogurt may have protected the $S$. thermophilus in yogurt.

The L. delbrueckii ssp. bulgaricus LB-12 log counts for the yogurt shelf life study as influenced by myrrh over 5 wk of storage are shown in Figure 2b. Log microbial counts for the myrrh and control yogurts decreased by 3.77 and $3.92 \log \mathrm{cfu} / \mathrm{g}$, respectively, between 0 and 5
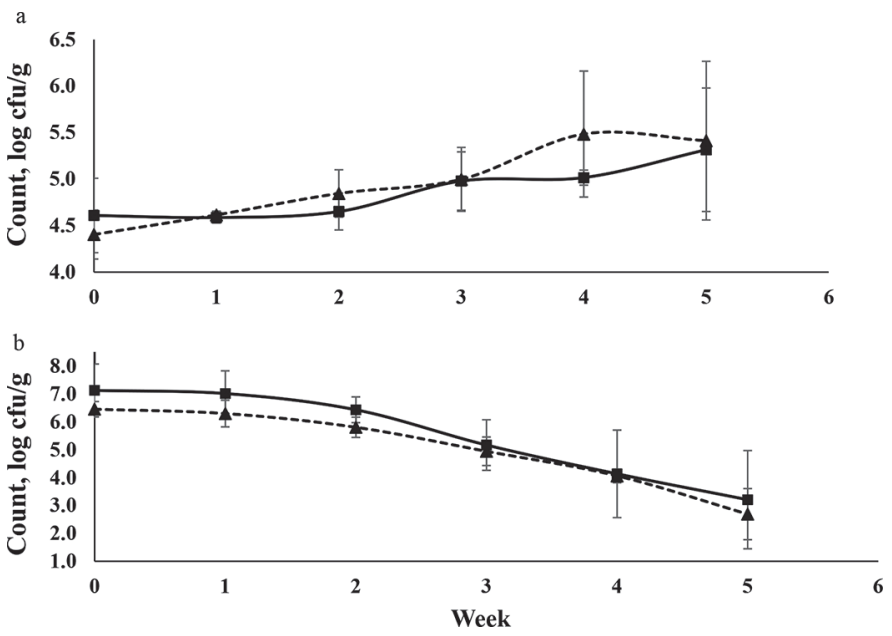

Figure 2. Log counts of (a) Streptococcus thermophilus ST-M5 and (b) Lactobacillus delbrueckii ssp. bulgaricus LB-12 counts in yogurt in the presence $(\boldsymbol{\Delta})$ and absence ( $)$ of myrrh over 5 wk of storage. Error bars represent SD.

wk. The intercept, slope of the regression line, $t$-value, $P$-value, and $\mathrm{R}^{2}$ value for $L$. delbrueckii ssp. bulgaricus counts as a function of storage time are shown in Table 1. As observed for the S. thermophilus log counts, we detected no significant difference in $L$. delbrueckii ssp. bulgaricus log counts between the myrrh-containing yogurts $(5.04 \pm 1.44 \log \mathrm{cfu} / \mathrm{mL})$ and the control $(5.52$ $\pm 1.81 \mathrm{og} \mathrm{cfu} / \mathrm{mL}$ ) or in the slopes of the regression lines for L. delbrueckii ssp. bulgaricus log counts versus time during storage of the myrrh and control samples. The $\log$ counts remained within $1 \log$ of each other during 5 wk of storage. The $1 \%$ myrrh supernatant was not strong enough to kill the L. delbrueckii ssp. bulgaricus LB-12 bacteria in yogurt.

The $\mathrm{pH}$ of yogurt during its 5 wk shelf life study is shown in Figure 3. We observed no significant difference in $\mathrm{pH}$ between the myrrh-containing yogurts and the controls at different storage times or in the slopes of the regression lines for $\mathrm{pH}$ versus time during storage of the yogurt samples. The $\mathrm{pH}$ values of all samples were

Table 1. The intercept (log count) and slope of the regression line (log count/wk), t-values, P-values, and $\mathrm{R}^{2}$ values for Streptococcus thermophilus ST-M5 log counts and Lactobacillus delbrueckii ssp. bulgaricus LB-12 log counts by week

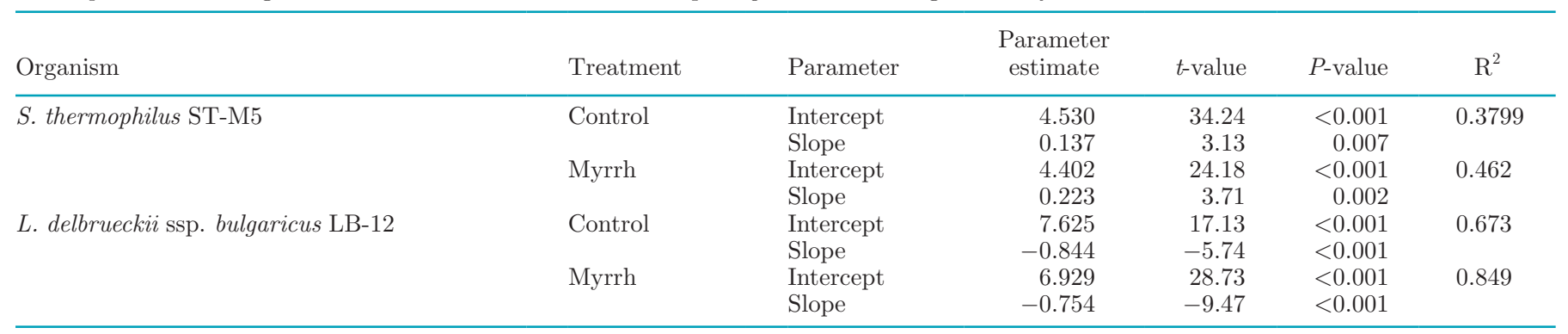




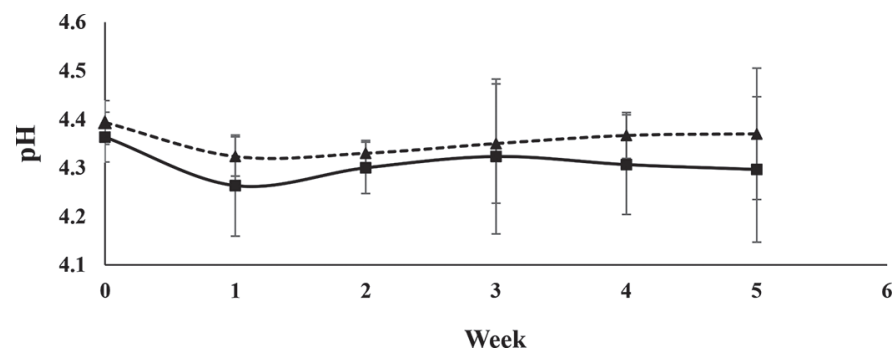

Figure 3. The pH of yogurts containing myrrh $(\boldsymbol{\Delta})$ and control over 5 wk of storage. Error bars represent SD.

within $0.1 \mathrm{pH}$ unit of each other in any given week. This may be due to the addition of the free hydroxyl ions originating from the myrrh/water supernatant. The free hydroxyl ions may have neutralized some of the lactic acid produced by S. thermophilus ST-M5 and L. delbrueckii ssp. bulgaricus LB-12 bacteria, resulting in a slight increase of the yogurt's pH compared with the control. Dairy products are able to bind or release ions, causing a small change in $\mathrm{pH}$ upon addition of an acid or alkali substance. Furthermore, dairy products generally have a high protein content, ensuring a relatively high buffering capacity due to the buffering effect of amino groups (Al-Dabbas et al., 2011). According to Mohamed et al. (2016), the $\mathrm{pH}$ values increased with increasing EO concentration. This increase may be due to the action of EO inhibition of acidity formation and the alkaline effect of the EO itself. During storage, $\mathrm{pH}$ values decreased slightly for all treatments. The decrease in $\mathrm{pH}$ during the first week of storage in the present study could be related to the production of lactic acid arising from lactose hydrolysis that likely occurred during storage.

Titratable acidity values for myrrh and control yogurts throughout 5 wk of storage are shown in Figure 4. The titratable acidity values remained steady around 1.1 to $1.2 \%$ (expressed as \% lactic acid) for myrrh and control yogurts throughout the 5 -wk storage period. We detected no significant differences in titratable acidity values between myrrh and control yogurts, among the

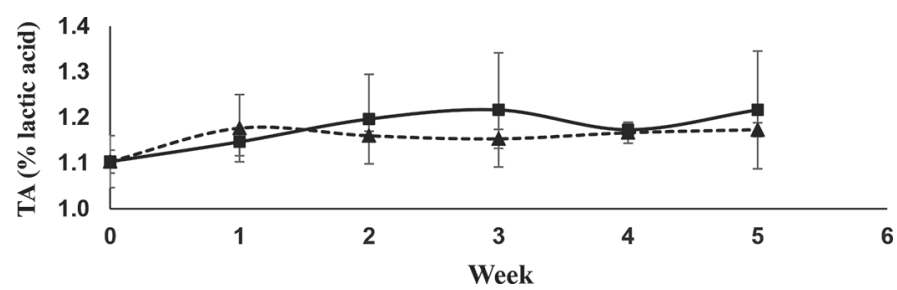

Figure 4. Titratable acidity expressed as percent lactic acid of yogurts containing myrrh $(\boldsymbol{\Delta})$ and control $(\boldsymbol{\square})$ over 5 wh of storage. Error bars represent SD. various storage times, or in the slopes of the regression lines for $\mathrm{pH}$ versus time during storage of the myrrhcontaining samples versus the controls.

In this study, we investigated the effect of an aqueous myrrh suspension on $S$. thermophilus and L. delbrueckii ssp. bulgaricus counts in both peptone and yogurt, and on resulting $\mathrm{pH}$ and titratable acidities. Yogurt culture bacteria can survive in the presence of an aqueous myrrh suspension in pure form and in the yogurt matrix with no significant effect on $\mathrm{pH}$ or titratable acidity of yogurt. Therefore, it may be possible to use an aqueous myrrh suspension in yogurt without adverse effects. Improvements in safety, shelf life, and organoleptic properties in yogurt containing an aqueous myrrh suspension could be subjects for further investigation.

\section{ACKNOWLEDGMENTS}

The authors appreciate the support of the Louisiana State University AgCenter (Baton Rouge) and Hatch funds. This article has been approved for publication by the director of the Louisiana Agricultural Experiment Station as manuscript number 2018-237-33409.

\section{REFERENCES}

Al-Dabbas, M. M., K. Al-Ismail, and B. M. Al-Abdullah. 2011. Effect of chemical composition on the buffering capacity of selected dairy products. Jordan J. Agric. Sci. 7:690-700.

Aryana, K. J., and D. W. Olson. 2017. A 100-year review: Yogurt and other cultured dairy products. J. Dairy Sci. 100:9987-10013.

Çakmakçi, S., E. Gündoğdu, E. Dağdemir, and U. Erdoğan. 2014. Investigation of the possible use of black cumin (Nigella sativa L.) essential oil on butter stability. Kafkas Univ. Vet. Fak. Derg. 20:533-539.

Dave, R. I., and N. P. Shah. 1996. Evaluation of media for selective enumeration of Streptococcus thermophilus, Lactobacillus delbrueckii ssp. bulgaricus, Lactobacillus acidophilus, and Bifidobacteria. J. Dairy Sci. 79:1529-1536.

Dave, R. I., and N. P. Shah. 1997. Viability of yoghurt and probiotic bacteria in yoghurts made from commercial starter cultures. Int. Dairy J. 7:31-41.

de Carvalho, R. J., G. T. de Souza, V. G. Honório, J. P. de Sousa, M. L. da Conceição, M. Maganani, and E. L. de Souza. 2015. Comparative inhibitory effects of Thymus vulgaris L. essential oil against Staphylococcus aureus, Listeria monocytogenes and mesophilic starter co-culture in cheese-mimicking models. Food Microbiol. 52:59-65.

FDA (Food and Drug Administration). 2018. 21CFR172.510: Natural flavoring substances and natural substances used in conjunction with flavors. Accessed Jun. 29, 2018. https://www.accessdata.fda .gov/scripts/cdrh/cfdocs/cfcfr/CFRSearch.cfm?fr $=172.510$.

Fetrow, C. W., and J. R. Avila. 2004. Professional's Handbook of Complementary \& Alternative Medicines, 3rd ed. Lippincott Williams \& Wilkins, Philadelphia, PA.

Fraternale, D., S. Sosa, D. Ricci, S. Genovese, F. Messina, S. Tomasini, F. Montanari, and M. C. Marcotullio. 2011. Anti-inflammatory, antioxidant and antifungal furanosesquiterpenoids isolated from Commiphora erythraea (Ehrenb.) Engl. resin. Fitoterapia 82:654661.

Hanuš, L. O., T. Řezanka, V. M. Dembitsky, and A. Moussaieff. 2005. Myrrh-Commiphora chemistry. Biomed. Pap. Med. Fac. Univ. Palacky Olomouc Czech Repub. 149:3-27. 
Hanuš, L. O., D. Rosenthal, T. Řezanka, V. M. Dembitsky, and A. Moussaief. 2008. Fast and easy GC/MS identification of myrrh resins. Pharm. Chem. J. 42:719-720.

Kim, S. Y., D. H. Kang, J. K. Kim, Y. G. Ha, J. Y. Hwang, T. Kim, and S. H. Lee. 2011. Antimicrobial activity of plant extracts against Salmonella Typhimurium, Escherichia coli O157:H7, and Listeria monocytogenes on fresh lettuce. J. Food Sci. 76:M41-M46.

Kostova, I., D. Dimitrov, M. Ivanova, R. Vlaseva, S. Damyanova, N. Ivanova, A. Stoyanova, and O. Gubenia. 2014. The possibilities of using of essential oils in dairy products. 2. Dill (Anethum graveolens). Ukr. Food J. 3:516-523.

Lotfy, M., G. Badra, W. Burham, and F. Alenzi. 2006. Combined use of honey, bee propolis and myrrh in healing a deep, infected wound in a patient with diabetes mellitus. Br. J. Biomed. Sci. 63:171-173.

Marcial, G. E., C. L. Gerez, M. N. de Kairuz, V. C. Araoz, C. Schuff, and G. F. de Valdez. 2016. Influence of oregano essential oil on traditional Argentinean cheese elaboration: Effect on lactic starter cultures. Rev. Argent. Microbiol. 48:229-235.

Mohamed, A. G., H. M. Abbas, J. M. Kassem, W. A. Gafour, and A. G. Attalah. 2016. Impact of myrrh essential oil as a highly effective antimicrobial agent in processed cheese spreads. Int. J. Dairy Sci. 11:41-51.
Moro, A., C. M. Librán, M. I. Berruga, M. Carmona, and A. Zalacain. 2015. Dairy matrix effect on the transference of rosemary (Rosmarinus officinalis) essential oil compounds during cheese making. J. Sci. Food Agric. 95:1507-1513.

Muramalla, T., and K. J. Aryana. 2011. Some low homogenization pressures improve certain probiotic characteristics of yogurt culture bacteria and Lactobacillus acidophilus LA-K. J. Dairy Sci. 94:3725-3738.

Parvez, S., K. A. Malik, S. Ah Kang, and H. Y. Kim. 2006. Probiotics and their fermented food products are beneficial for health. J. Appl. Microbiol. 100:1171-1185.

Sharma, R., B. Bhaskar, B. S. Sanodiya, G. S. Thakur, P. Jaiswal, N. Yadav, A. Sharma, and P. S. Bisen. 2014. Probiotic efficacy and potential of Streptococcus thermophilus modulating human health: A synoptic review. J. Pharm. Biol. Sci. 9:52-58.

Vinderola, C. G., N. Bailo, and J. A. Reinheimer. 2000. Survival of probiotic microflora in Argentinian yoghurts during refrigerated storage. Food Res. Int. 33:97-102.

Wehr, H. M., J. F. Frank, and A. P. H. Association. 2004. Standard Methods for the Examination of Dairy Products. American Public Health Association, Washington, DC. 